\title{
Multiple Mediators and Mechanisms Are Involved in the Adaptive Cytoprotection Provided by Certain Mild Irritants
}

\author{
Yoshifumi Hatakeyama, Masahiko Matsuo, Masaaki Tomoi, Jo Mori and Masanobu Kohsaka \\ Department of Pharmacology, Product Development Laboratories, Fujisawa Pharmaceutical Co., Ltd., \\ 1-6, Kashima 2-chome, Yodogawa-ku, Osaka 532, Japan \\ Received April 23, $1993 \quad$ Accepted July 19, 1993
}

\begin{abstract}
We investigated the participation of prostaglandins (PG) and nitric oxide (NO) in adaptive cytoprotection using $0.6 \mathrm{~N} \mathrm{HCl}$-induced gastric lesions in the rat stomach. Indomethacin reversed the protective effect of $0.2 \mathrm{~N} \mathrm{HCl}$ more strongly than that of $0.35 \mathrm{~N} \mathrm{HCl}$, both of which markedly inhibited $\mathrm{HCl}$ ulcer. $N^{G}$-Nitro-l-arginine (L-NNA) did not affect the protective effect afforded by either $0.2 \mathrm{~N} \mathrm{HCl}$ or 0.35 $\mathrm{N} \mathrm{HCl}$. Combined pretreatment with indomethacin and L-NNA did not diminish the protective action induced by $0.35 \mathrm{~N} \mathrm{HCl}$, but almost completely abolished the indomethacin-resistant protection afforded by 0.1 $\mathrm{N} \mathrm{NaOH}$. Acid mild irritant increased the gastric fluid volume concentration-dependently, whereas alkaline mild irritant had little or no effect on the volume. These results suggest that: 1) The mediators involved in adaptive cytoprotection afforded by $0.1 \mathrm{~N} \mathrm{NaOH}$ may be fully ascribed to $\mathrm{PG}$ and $\mathrm{NO}$;2) $\mathrm{PG}$ is a major mediator in the protection induced by $0.2 \mathrm{~N} \mathrm{HCl}$; 3) In the case of $0.35 \mathrm{~N} \mathrm{HCl}$, the mediators remain to be determined since increased gastric fluid volume could contribute to the protection through dilution. These findings thus may indicate that multiple mediators and mechanisms are implicated in adaptive cytoprotection.
\end{abstract}

Keywords: Adaptive cytoprotection, Arginine, Mild irritant, Nitric oxide, Prostaglandin

The term "adaptive cytoprotection" was coined by Robert et al. for the phenomenon that pretreatment with mild irritants enables the gastric mucosa to withstand the damage caused by exposure to various noxious agents. It has been believed that this event is mediated by endogenous prostaglandins (PG) because: 1) Adaptive cytoprotection is counteracted by pretreatment with indomethacin, a potent cyclooxygenase inhibitor; and 2) Exposure to mild irritants enhances the generation of PG by the gastric mucosa (1-3). Since 1988, however, several reports have questioned the involvement of $P G$ in this phenomenon. It has been shown that adaptive cytoprotection occurs even when PG generation is almost completely inhibited $(4,5)$. Furthermore, Balaa (6) has suggested the existence of endogenous protective products which are different from PG, and that they are responsible for the mediation of adaptive cytoprotection. More recently, NO has been suggested to participate in the gastric mucosal protection $(7-9)$.

Taken together, it seems that there has been disagreement as to whether PG are involved in adaptive cytoprotection and whether the mediators other than PG such as NO participate in adaptive cytoprotection. We speculated that the concentration and/or the kind of mild irritants applied could provide clues to solving these problems. Therefore, we carried out the present study to investigate the involvement of $P G$ and $N O$ in adaptive cytoprotection by: 1) examining the effect of indomethacin on the protective effects of $0.2 \mathrm{~N}$ and $0.35 \mathrm{~N} \mathrm{HCl}$, 2) comparing the effects of acid mild irritant and alkaline mild irritant. We discuss here a possible clarification of the mediators responsible for adaptive cytoprotection.

\section{MATERIALS AND METHODS}

\section{Induction of gastric mucosal injury}

Male Sprague-Dawley rats weighing between 166 and $219 \mathrm{~g}$ were used in this study. They were housed in cages with wide mesh bottoms to prevent coprophagy, and they were fasted but allowed free access to tap water for $20 \mathrm{hr}$ prior to the start of the experiments.

Gastric mucosal lesions were induced as described by Robert et al. (2). Groups of six to eight rats were given $1 \mathrm{ml}$ of $0.6 \mathrm{~N} \mathrm{HCl}$ by oral intubation and then sacrificed 
$1 \mathrm{hr}$ later. The stomachs were dissected out, inflated by injecting $13 \mathrm{ml}$ of $2 \%$ formalin, and kept immersed in $2 \%$ formalin for $30 \mathrm{~min}$ to fix the mucosa.

After opening the stomach along the greater curvature, the length $(\mathrm{mm})$ of visible necrotic lesions in the glandular area were measured macroscopically and summed up per stomach as a lesion index. Mild irritants were given orally $30 \mathrm{~min}$ before $0.6 \mathrm{~N} \mathrm{HCl}$ treatment. Indomethacin (10 $\mathrm{mg} / \mathrm{kg}$ ) was injected subcutaneously $60 \mathrm{~min}$ before administration of mild irritants. In the experiments with $N^{G}$ nitro-L-arginine (L-NNA), it was given orally $20 \mathrm{~min}$ before the treatment with mild irritants. L-Arginine was injected intravenously $10 \mathrm{~min}$ before the injection of LNNA. The dose of indomethacin was selected to show 93.4\% inhibition of $\mathrm{PGE}_{2}$ content in the gastric mucosa, while the dose of L-NNA was selected to induce a marked increase of arterial blood pressure (unpublished data, Y. Hatakeyama et al.).

\section{Measurement of gastric fluid volume}

Drug treatments were performed according to the time schedule described above except that the animals were killed $30 \mathrm{~min}$ after mild irritant treatment. The esophagogastric junction and pylorus were clipped and gastric juice in the cavity was collected in the tube. After centrifugation (2000 rpm, $10 \mathrm{~min})$, gastric fluid volume was measured by subtracting the solid volume from the total volume.

\section{Preparation of drugs}

L-NNA was obtained from the Sigma Chemical Co. (St. Louis, MO, USA); it was suspended in $0.1 \%$ methylcellulose solution. L-Arginine, obtained from Katayama Chemical (Osaka), was dissolved in saline. The agents were prepared immediately before the experiment and administered in a volume of $5 \mathrm{ml} / \mathrm{kg}$, except in the case of subcutaneous treatment when they were given in a volume of $2 \mathrm{ml} / \mathrm{kg}$.

\section{Statistical analyses}

Data are expressed as the mean \pm S.E. from six to eight rats per group. Statistical analyses were performed by one way analysis of variance followed by Dunnett's multiple comparison test for multi group comparisons and, when appropriate, by the unpaired Student's $t$-test. Values of $\mathrm{P}<0.05$ were considered to be statistically significant.

\section{RESULTS}

Effects of indomethacin and/or L-NNA on the protective actions of acid mild irritants against $0.6 \mathrm{~N} \mathrm{HCl}$-induced gastric lesions

Oral administration of $0.6 \mathrm{~N} \mathrm{HCl}$ resulted in macro- scopically visible necrosis in the glandular part of the stomach. Both $0.2 \mathrm{~N}$ and $0.35 \mathrm{~N} \mathrm{HCl}$ conferred significant protection against damage caused by $0.6 \mathrm{~N} \mathrm{HCl}$ $(87.4 \%, 93.9 \%$ inhibition, respectively; Fig. 1$)$. Interestingly, indomethacin, which by itself aggravated the gastric damage from $85.8 \pm 15.7 \mathrm{~mm}$ in the control to $121.9 \pm 4.5 \mathrm{~mm}$, reversed the protective action of $0.2 \mathrm{~N}$ $\mathrm{HCl}$ more strongly than $0.35 \mathrm{~N} \mathrm{HCl}$, the inhibition being $32.9 \%(\mathrm{P}<0.01)$ and $80.4 \%(\mathrm{P}<0.01)$, respectively, although the protection afforded by $0.2 \mathrm{~N} \mathrm{HCl}$ with pretreatment of indomethacin was still siginificant. Pretreatment with L-NNA $(10 \mathrm{mg} / \mathrm{kg})$ hardly affected the protective actions of either $0.2 \mathrm{~N}$ or $0.35 \mathrm{~N} \mathrm{HCl}$, while it aggravated the extent of $0.6 \mathrm{~N} \mathrm{HCl}$-induced damage (Fig. 2).

Also, pretreatment with L-NNA ( 10 or $32 \mathrm{mg} / \mathrm{kg}$ ) in addition to indomethacin conferred no reversal of the indomethacin-resistant protection, the inhibition being 64.6 , 55.0 and $57.6 \%$ at the doses of 0,10 and $32 \mathrm{mg} / \mathrm{kg}$, respectively, showing that L-NNA hardly reversed the indomethacin-resistant protection (Fig. 3).

Effects of indomethacin and/or L-NNA on the protective actions of alkaline mild irritant against $0.6 \mathrm{~N} \mathrm{HCl-in-}$ duced gastric lesions

The results of the L-NNA study are presented in Fig. 4.

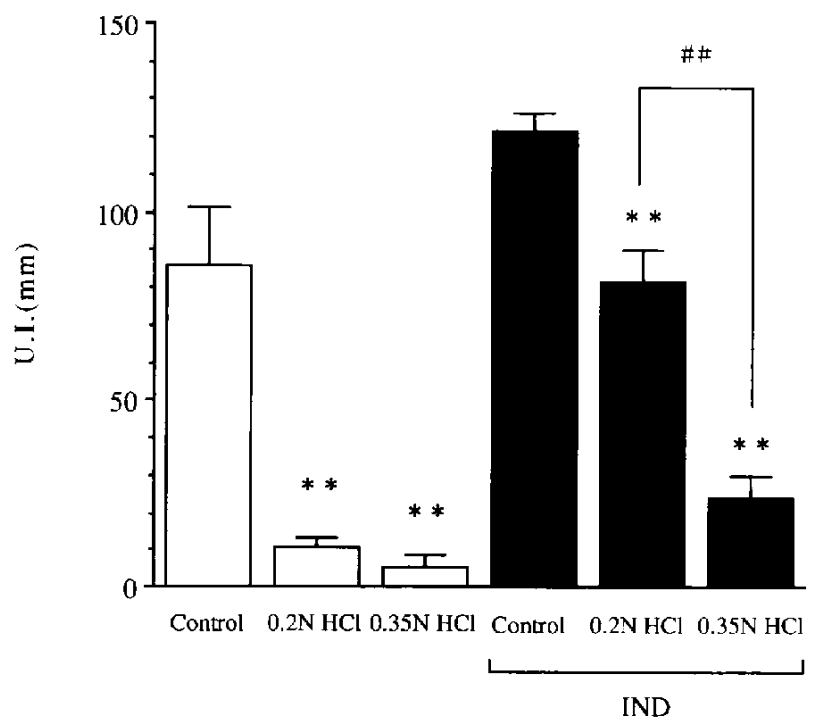

Fig. 1. Effects of indomethacin (IND) on the protective actions of $0.2 \mathrm{~N} \mathrm{HCl}$ and $0.35 \mathrm{~N} \mathrm{HCl}$ against gastric lesions induced by $0.6 \mathrm{~N}$ $\mathrm{HCl}$. The animals were given $1 \mathrm{ml}$ of $0.6 \mathrm{~N} \mathrm{HCl}$ orally and were sacrificed $1 \mathrm{hr}$ later. Mild irritants were administered orally $30 \mathrm{~min}$ before $\mathrm{HCl}$ treatment. Indomethacin was given subcutaneously 60 min before mild irritant treatment. Data are presented as the mean \pm S.E. from $6-8$ rats per group. ${ }^{* *}$ : Significantly different from the corresponding control group at $\mathbf{P}<0.01$. ${ }^{\text {Hignificantly }}$ different from the indomethacin plus $0.2 \mathrm{~N} \mathrm{HCl}$ group at $\mathrm{P}<0.01$. 


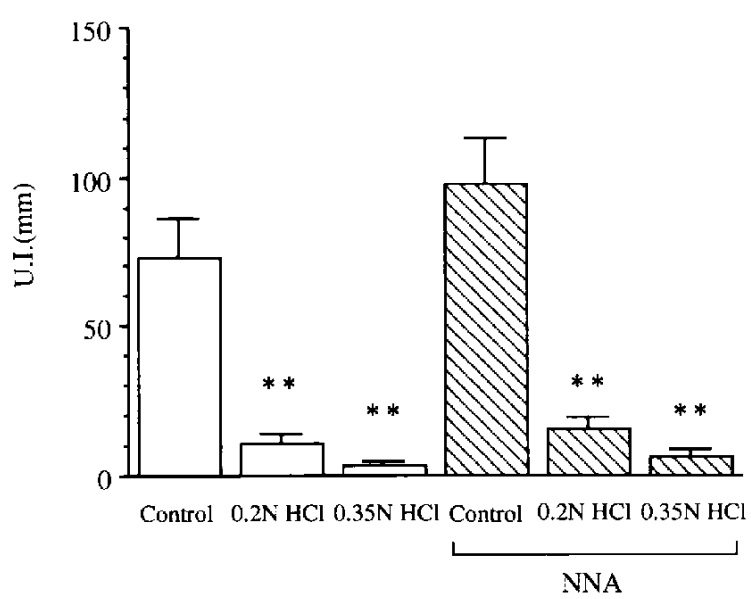

Fig. 2. Effects of $N^{G}$-nitro-L-arginine (NNA) on the protective actions of $0.2 \mathrm{~N} \mathrm{HCl}$ and $0.35 \mathrm{~N} \mathrm{HCl}$ against gastric lesions induced by $0.6 \mathrm{~N} \mathrm{HCl}$. NNA $(10 \mathrm{mg} / \mathrm{kg})$ was given orally $20 \mathrm{~min}$ before administration of mild irritants. Data are presented as the mean \pm S.E. from 7 rats per group. ${ }^{* *}$ : Significantly different from the corresponding control group at $\mathrm{P}<0.01$.

The lesion index was $69.6 \pm 8.9 \mathrm{~mm}$ in the control rats. $0.1 \mathrm{~N} \mathrm{NaOH}$ significantly attenuated the $0.6 \mathrm{~N} \mathrm{HCl}$-induced mucosal lesions by $67.8 \%(\mathrm{P}<0.01)$. L-NNA $(10$ $\mathrm{mg} / \mathrm{kg}$ ), which augmented the gastric lesions by $42.7 \%$, had little or no effect on the protective action of $0.1 \mathrm{~N}$

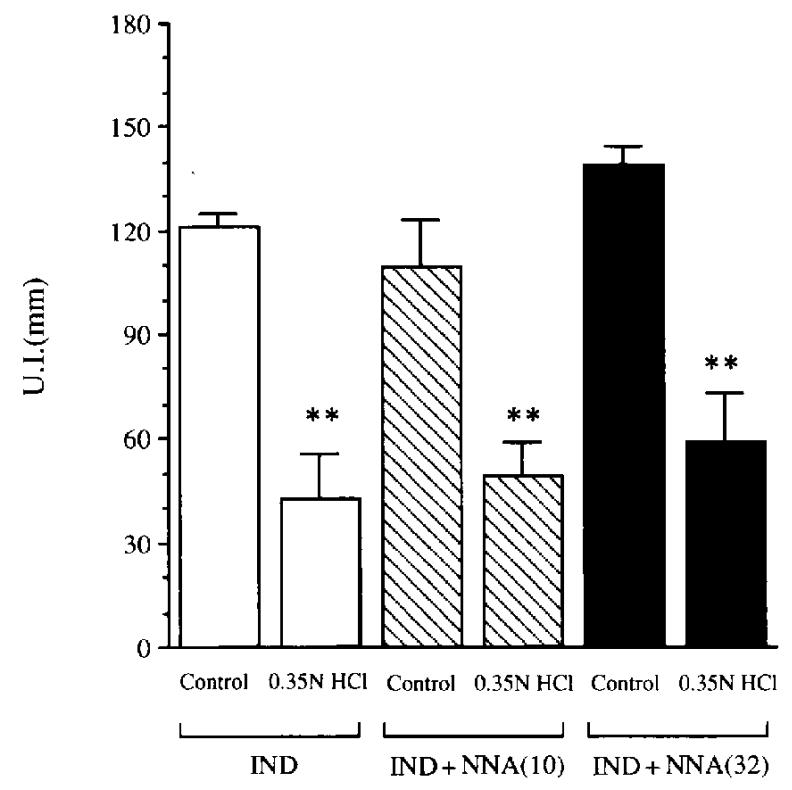

Fig. 3. Effects of indomethacin and combined treatment with indomethacin and NNA $(10,32 \mathrm{mg} / \mathrm{kg})$ on the protective actions of 0.35 $\mathrm{N} \mathrm{HCl}$ against gastric lesions induced by $0.6 \mathrm{~N} \mathrm{HCl}$. Indomethacin (s.c.) and NNA (p.o.) were given $60 \mathrm{~min}$ and $20 \mathrm{~min}$ before administration of $0.35 \mathrm{~N} \mathrm{HCl}$, respectively. Data are expressed as the mean \pm S.E. from 7 rats per group. ${ }^{* *}$ : Significantly different from the corresponding control group at $\mathrm{P}<0.01$.

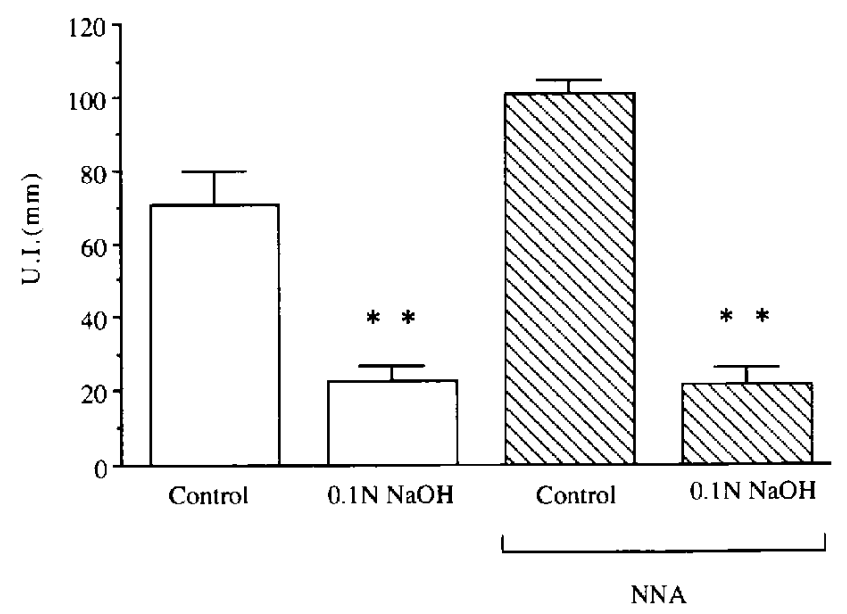

Fig. 4. Effects of NNA on the protective actions of $0.1 \mathrm{~N} \mathrm{NaOH}$ against gastric lesions produced by $0.6 \mathrm{~N} \mathrm{HCl}$. NNA $(10 \mathrm{mg} / \mathrm{kg})$ was given orally $20 \mathrm{~min}$ before administration of $0.1 \mathrm{~N} \mathrm{NaOH}$. Data are presented as the mean \pm S.E. from 7 rats per group. **: Significantly different from the corresponding control group at $\mathrm{P}<0.01$.

$\mathrm{NaOH}$, the inhibition being $78.4 \%(\mathrm{P}<0.01)$. On the other hand, as shown in Fig. 5 , the protective action of $0.1 \mathrm{~N} \mathrm{NaOH}$ was not attenuated by the pretreatment with indomethacin but was almost completely abolished by combined pretreatment with indomethacin and L-NNA $(10 \mathrm{mg} / \mathrm{kg})$. Furthermore, L-arginine $(300 \mathrm{mg} / \mathrm{kg}$, i.v.) restored the indomethacin-resistant protection of $0.1 \mathrm{~N}$ $\mathrm{NaOH}$.

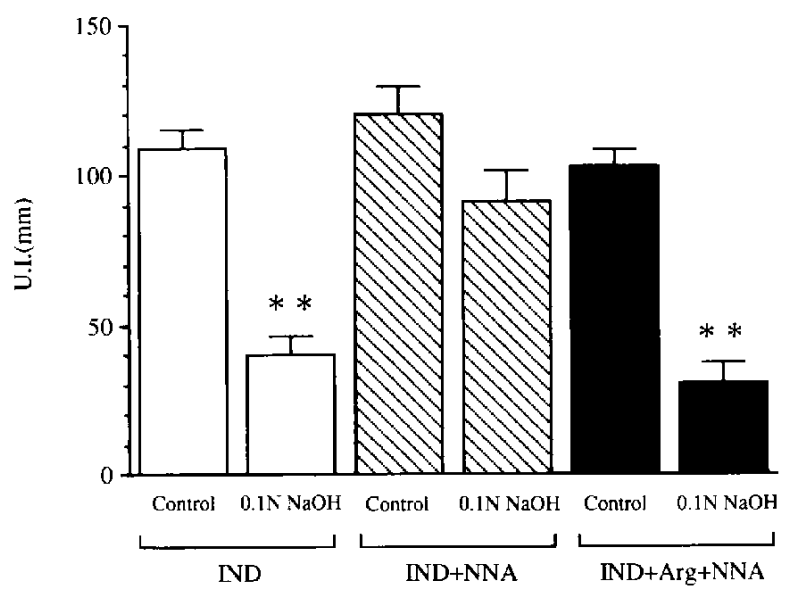

Fig. 5. Effects of indomethacin and combined treatment with indomethacin and NNA $(10 \mathrm{mg} / \mathrm{kg})$ on the protective actions of $0.1 \mathrm{~N}$ $\mathrm{NaOH}$ against gastric lesions produced by $0.6 \mathrm{~N} \mathrm{HCl}$. Indomethacin (s.c.) and NNA (p.o.) were given $60 \mathrm{~min}$ and $20 \mathrm{~min}$ before administration of $0.1 \mathrm{~N} \mathrm{NaOH}$, respectively. L-Arginine (Arg) was given intravenously $10 \mathrm{~min}$ before administration of NNA. Data are expressed as the mean \pm S.E. from 7 rats per group. ${ }^{* *}$ : Significantly different from the corresponding control group at $\mathrm{P}<0.01$. 
Table 1. Effects of mild irritants on gastric fluid volume in rats

\begin{tabular}{llcc}
\hline & Treatment & $\mathrm{N}$ & $\begin{array}{c}\text { Gastric fluid volume } \\
\text { (ml) }\end{array}$ \\
\hline Exp. 1 & Control & 7 & $0.17 \pm 0.09$ \\
& $0.2 \mathrm{~N} \mathrm{HCl}$ & 7 & $0.56 \pm 0.07^{*}$ \\
& $0.35 \mathrm{~N} \mathrm{HCl}$ & 7 & $0.89 \pm 0.07^{* *}$ \\
& $0.1 \mathrm{~N} \mathrm{NaOH}$ & 7 & $0.34 \pm 0.16$ \\
Exp. 2 & IND & 7 & $0.03 \pm 0.02$ \\
& IND + 0.2 N HCl & 7 & $0.50 \pm 0.10^{* *}$ \\
& IND +0.35 N HCl & 7 & $0.93 \pm 0.09^{* *}$ \\
Exp. 3 & IND + L-NNA & 7 & $0.06 \pm 0.02$ \\
& IND + L-NNA +0.35 N HCl & 7 & $1.10 \pm 0.07^{* *}$ \\
\hline
\end{tabular}

Animals were killed $30 \mathrm{~min}$ after oral administration of mild irritants, and gastric fluid in the cavity was collected. In Exp. 2, indomethacin (IND, $10 \mathrm{mg} / \mathrm{kg}$ ) was given subcutaneously $60 \mathrm{~min}$ before administration of mild irritants. In Exp. 3, $N^{G}$-nitro-L-arginine (LNNA, $10 \mathrm{mg} / \mathrm{kg}$ ) was given orally $20 \mathrm{~min}$ before administration of mild irritants. Values are presented as the mean \pm S.E. from 7 rats per group. ${ }^{*}, * *$ : Significantly different from the corresponding control group at $\mathrm{P}<0.05, \mathrm{P}<0.01$, respectively.

\section{Effects of mild irritants on gastric fluid volume}

The results are presented in Table 1. Acid mild irritant increased the gastric fluid volume significantly and concentration-dependently. Unlike the acid mild irritant, alkaline mild irritant scarcely increased the volume. Neither pretreatment with indomethacin nor combined pretreatment with indomethacin and L-NNA inhibited the increase of gastric fluid volume caused by acid mild irritant.

\section{DISCUSSION}

We found that indomethacin counteracted the protective effect of $0.2 \mathrm{~N} \mathrm{HCl}$ against $0.6 \mathrm{~N} \mathrm{HCl}$-induced gastric lesions, but scarcely affected that of $0.35 \mathrm{~N} \mathrm{HCl}$. This may indicate that endogenous protective mediators other than PG or additional mechanisms become involved in adaptive cytoprotection when the concentration of acid mild irritant is increased. In the case of $0.2 \mathrm{~N} \mathrm{HCl}$, the protection is mainly afforded by $\mathrm{PG}$, whereas the protection induced by $0.35 \mathrm{~N} \mathrm{HCl}$ may result from other mediators as well or additional mechanisms which were not exhibited in the protection induced by $0.2 \mathrm{~N} \mathrm{HCl}$.

There is disagreement as to whether PG are truly involved in adaptive cytoprotection. Hawkey et al. (4) have shown that indomethacin failed to reverse adaptive cytoprotection, even though it markedly inhibited $\mathrm{PGE}_{2}$ release by more than $80 \%$ and that $20 \%$ ethanol did not stimulate the ex vivo release of $\mathrm{PGE}_{2}$. These results are similar to the findings of Wallace (5), who noted that indomethacin never blocked the adaptive cytoprotection afforded by $1 \mathrm{M} \mathrm{NaCl}$ against $70 \%$ ethanol-induced damage using an ex vivo gastric chamber preparation, although the dose of indomethacin applied was sufficient to cause a profound depression of 6-keto $\mathrm{PGF}_{1 \alpha}$ synthesis. In addition, MacNaughton et al. (10) showed that indomethacin did not significantly affect the ability of 0.25 $\mathrm{N} \mathrm{HCl}$ to reduce the lesions caused by ethanol. Also, there are reports $(6,11,12)$ which suggest that mediators other than PG might be responsible for adaptive cytoprotection. These differences in the reversibility of indomethacin may be explained in part by the present finding that the influence of indomethacin on adaptive cytoprotection depends on the concentration of acid mild irritant. It seems that the concentration of mild irritants used should be taken into account when comparing the different reports concerning adaptive cytoprotection. On the other hand, the present study disagrees with the findings of Takeuchi et al. (13) that the protection induced by $0.35 \mathrm{~N} \mathrm{HCl}$ against $0.6 \mathrm{~N} \mathrm{HCl}$-induced gastric injury was completely reversed by the prior treatment with indomethacin. The dose of indomethacin does not seem to account for this discrepancy because it was ascertained to be sufficient to cause the profound suppression of PG generation in each study. It is noted that in our study, $0.2 \mathrm{~N}$ $\mathrm{HCl}$ submaximaly inhibited $(87.4 \%)$ the $0.6 \mathrm{~N} \mathrm{HCl}$-induced gastric lesion, whereas $0.25 \mathrm{~N} \mathrm{HCl}$ only provided a mild inhibition in their study. Considering this difference in susceptibility to the mild irritant in preventing gastric lesion formation, the difference in strains of rats might account for this discrepancy (K. Takeuchi et al. used Donryu rats, but we used Sprague-Dawley rats).

It is still unclear whether mild irritants really stimulate endogenous PG generation. Hawkey et al. (4) have shown that $20 \%$ ethanol never stimulated ex vivo release of $\mathrm{PGE}_{2}$, whereas Robert et al. (2) reported that $\mathrm{NaOH}$ given at concentrations up to $0.1 \mathrm{M}$ significantly increased both the $\mathrm{PGE}_{2}$ and $\mathrm{PGF}_{2 \alpha}$ contents of the gastric mucosa. We therefore investigated whether $0.35 \mathrm{~N} \mathrm{HCl}$ stimulated $\mathrm{PG}$ generation, and found that it increased the $\mathrm{PGE}_{2}$ content of the gastric mucosa by $25.4 \%$, the concentration of 6-keto $\mathrm{PGF}_{1 \alpha}$ in the plasma by $21.7 \%$ and the concentration of $\mathrm{PGE}_{2}$ in the plasma by $128.5 \%$, although none of these effects were significant (unpublished data, Y. Hatakeyama et al.), indicating that it is difficult to demonstrate the increment in $\mathrm{PG}$ in response to mild irritants by measuring a specific type of PG in a specific part of the stomach. This may explain in part the obscure point as to whether mild irritants stimulate PG synthesis. On the whole, however, it can be concluded that mild irritants stimulate endogenous PG synthesis.

As demonstrated in this study, the protection provided by $0.1 \mathrm{~N} \mathrm{NaOH}$ withstood the pretreatment with indomethacin, suggesting that $0.1 \mathrm{~N} \mathrm{NaOH}$ is able to elicit the 
release or the formation of non $\mathrm{PG}$ endogenous protective mediators. Furthermore studies with $0.1 \mathrm{~N} \mathrm{NaOH}$ showed that neither indomethacin nor L-NNA could affect adaptive cytoprotection, whereas the protection was reversed by combined pretreatment with indomethacin and L-NNA. This finding indicates that the involvement of PG in adaptive cytoprotection cannot be excluded even when indomethacin alone scarcely affects the protection of some drugs, and that major mediators participating in adaptive cytoprotection provided by $0.1 \mathrm{~N}$ $\mathrm{NaOH}$ are PG and NO. Archer and Hampl (14), who recently showed that arginine analogs like L-NNA and $N^{G}$ monomethyl-L-arginine (L-NMMA) had a direct vasoconstrictor effect on vascular smooth muscle not due to NO synthesis inhibition and that L-NMMA is a partial agonist for NO synthesis, brought attention to the use of arginine analogs as specific inhibitors of NO synthesis. The present study, however, demonstrated that L-arginine restored the indomethacin-resistant protection induced by $0.1 \mathrm{~N} \mathrm{NaOH}$ which was abolished by the combined pretreatment with indomethacin and L-NNA, indicating that $\mathrm{NO}$ is involved in adaptive cytoprotection.

Recent studies showed that NO could be involved in the protective actions of some antiulcer drugs such as carbenoxolone and sucralfate $(8,15)$. Lambrecht and Peskar (9) examined the effect of L-NNA pretreatment on the protective actions of some mild irritants against ethanol-induced gatric lesions and found that L-NNA counteracted the protective action by $20 \%$ ethanol and $0.1 \mathrm{~N} \mathrm{NaOH}$ but not that by $0.3 \mathrm{~N} \mathrm{HCl}$ and $5 \% \mathrm{NaCl}$, suggesting that NO is involved in the protective activity of some but not all mild irritants. However, we found that reversal of the protection afforded by $0.1 \mathrm{~N} \mathrm{NaOH}$ with L-NNA pretreatment could be observed only when rats were pretreated with indomethacin, whereas Lambrecht and Peskar (9) showed the same result without pretreatment with indomethacin. The reason for this difference is not known.

At present, the mechanisms involved in adaptive cytoprotection have not yet been fully elucidated. Since the irritative actions of necrotizing agents are attributed to their high concentration, keeping the tissue concentration of irritants below a critical level that causes damage by lowering the concentration of mild irritant (16) or increasing the mucosal blood flow which leads to the elimination of irritants diffusing into the mucosa from the lumen (17) may be one of the most likely mechanisms. As for the dilution, it could occur within the gastric mucosa or in the gastric cavity. The mucoid cap which is the layer of surface debris formed after exposure to mild irritants and acts as a physical barrier, diluting necrotizing agents to a level insufficient to cause deeper damage $(18,19)$, however, does not appear to be responsible for adaptive cytoprotection, although it seems to play a role in providing a protecting cover that is conducive to promoting rapid restitution (5, 20). Recently, a new concept for the mechanism of gastric mucosal protection has been introduced (16) which is referred to as the histodilutional barrier. This barrier is ascribed to the increased vascular permeability which may act to dissipate the concentration of necrotizing agents. We investigated the involvement of the dilution due to the fluid in the gastric cavity (luminal dilution). Acid mild irritant concentration-dependently increased the fluid volume in the gastric cavity. Yet, this increase is not responsible for the protection provided by $0.2 \mathrm{~N} \mathrm{HCl}$, because indomethacin had no influence on the fluid volume caused by $0.2 \mathrm{~N} \mathrm{HCl}$, although it counteracted the protective effect afforded by $0.2 \mathrm{~N} \mathrm{HCl}$. The increased volume caused by $0.35 \mathrm{~N} \mathrm{HCl}$ which reached $0.9 \mathrm{ml}$ or more is not negligible as a mechanism for the protection. Therefore, one needs to inhibit the increase in fluid volume or remove the increased gastric fluid in order to investigate the mediator-based protection afforded by $0.35 \mathrm{~N} \mathrm{HCl}$.

In conclusion, the present study demonstrated that neither indomethacin nor L-NNA mitigated adaptive cytoprotection afforded by $0.1 \mathrm{~N} \mathrm{NaOH}$, whereas it was almost completely abolished by the combined pretreatment with indomethacin and L-NNA, indicating that the mediators implicated in the protection afforded by $0.1 \mathrm{~N}$ $\mathrm{NaOH}$ are ascribed to $\mathrm{PG}$ and NO. Also, indomethacin failed to reverse the protection provided by $0.35 \mathrm{~N} \mathrm{HCl}$, which was accompanied by the increased fluid volume in the gastric cavity, although it counteracted the protection afforded by $0.2 \mathrm{~N} \mathrm{HCl}$. These results indicate that indomethacin cannot reverse the protection afforded by: 1) multiple endogenous mediators because some of them are capable of inhibiting the gastric lesions submaximally without any contribution of $P G, 2$ ) mechanisms such as dilution that is not caused by PG, meaning that the failure of indomethacin to reverse adaptive cytoprotection does not necessarily exclude $P G$ from the mediators participating in adaptive cytoprotection. Further studies are required to clarify the mediators, which are not inflammatory and do not protect the gastric mucosa through luminal dilution, implicated in the protection provided by $0.35 \mathrm{~N}$ $\mathrm{HCl}$.

\section{REFERENCES}

1 Robert, A., Lancaster, C., Hanchar, A.J. and Nezamis, J.E.: Mild irritants prevent gastric necrosis through prostaglandin formation: histological study. Gastroenterology 74, 1086 (1978)

2 Robert, A., Nezamis, J.E., Lancaster, C., Davis, J.P., Field, S.O. and Hanchar, A.J.: Mild irritants prevent gastric necrosis through "adaptive cytoprotection" mediated by prostaglandins. Am. J. Physiol. 245, G113-G121 (1983)

3 Chaudhury, T.K. and Robert, A.: Prevention by mild irritants of gastric necrosis produced in rats by sodium taurocholate. 
Dig. Dis. Sci. 25, 830-836 (1980)

4 Hawkey, C.J., Kemp, R.T., Walt, R.P., Bhaskar, N.K., Davies, J. and Filipowicz, B.: Evidence that adaptive cytoprotection in rats is not mediated by prostaglandins. Gastroenterology 94, 948-954 (1988)

5 Wallace, J.L.: Increased resistance of the rat gastric mucosa to hemorrhagic damage after exposure to an irritant: role of the "mucoid cap" and prostaglandin synthesis. Gastroenterology 94, 22-32 (1988)

6 Balaa, M.A.: Release of protective products, different from prostaglandins, by rat stomachs exposed to mild irritant. Dig. Dis. Sci. 34, 429-435 (1989)

7 Peskar, B.M., Respondek, M., Müller, K.M. and Peskar, B.A.: A role for nitric oxide in capsaicin-induced gastroprotection. Eur. J. Pharmacol, 198, 113-114 (1991)

8 Dembinska-Kiec, A., Pallapies, D., Simmet, Th., Peskar, B.M. and Peskar, B.A.: Effect of carbenoxolone on the biological activity of nitric oxide; relation to gastroprotection. Br. J. Pharmacol. 104, 811-816 (1991)

9 Lambrecht, N. and Peskar, B.M.: Role of nitric oxide (NO) in the gastroprotection by mild irritants in the rat stomach. Gastroenterology 102, A105 (1992)

10 MacNaughton, W.K., Williamson, T.E. and Morris, G.P.: Adaptive cytoprotection by $0.25 \mathrm{M} \mathrm{HCl}$ is truly "cytoprotective" and may not depend upon elevated levels of prostaglandin synthesis. Can. J. Physiol. Pharmacol. 66, 1075-1081 (1988)

11 MacNaughton, W.K. and Wallace, J.L.: A role for dopamine as an endogenous protective factor in the rat stomach. Gastroenterology 96, 972-980 (1989)

12 Tepperman, B.L., Soper, B.D. and Morris, G.P.: Effect of sialoadenectomy on adaptive cytoprotection in the rat. Gastroenterology 97, 123-129 (1989)
13 Takeuchi, K., Nishiwaki, H., Furukawa, O. and Okabe, S.: Cytoprotective action of histamine against $0.6 \mathrm{~N} \mathrm{HCl}$-induced gastric mucosal injury in rats; comparative study with adaptive cytoprotection induced by exogenous acid. Japan. J. Pharmacol. 44, 335-344 (1987)

14 Archer, S.L. and Hampl, V.: $N^{G}$-Monomethyl-L-arginine causes nitric oxide synthesis in isolated arterial rings: trouble in paradise. Biochem. Biophys. Res. Commun. 188, 590-596 (1992)

15 Konturek, S.J., Brzozowski, T., Majka, J. and Czarnobilski, K.: Nitric oxide in gastroprotection by sucralfate, mild irritant and nocloprost: role of mucosal blood flow. Gastroenterology 102, A101 (1992)

16 Dupuy, D., Kronauge, J.F., Jones, A.G. and Szabo, S.: Gastric mucosal protection may be mediated through increases in vascular permeability which create a histodilutional barrier. Gastroenterology 94, A615 (1988)

17 Gislason, H., Herfjord, J.K., Guttu, K., Grong, K., Gronbech, J.E., Ulvik, R. and Svanes, K.: Adaptive protection related to clearance of ethanol in gastric mucosa of cats. Scand. J. Gastroenterol. 28, $361-368$ (1993)

18 Wallace, J.L. and Whittle, B.J.R.: The role of extracellular mucus as a protective cap over gastric mucosal damage. Scand. J. Gastroenterol. 21, Supp. 125, 79-84 (1986)

19 Allen, A., Hutton, D.A., Leonard, A.J., Pearson, J.P. and Sellers, L.A.: The role of mucus in the protection of the gastroduodenal mucosa. Scand. J. Gastroenterol. 21, Supp. 125, 71-77 (1986)

20 Wallace, J.L. and Mcknight, G.W.: The mucoid cap over superficial gastric damage in the rat: a high-pH microenvironment dissipated by nonsteroidal antiinflammatory drugs and endothelin. Gastroenterology 99, 295-304 (1990) 